\title{
Article \\ Inhibition of WHSC1 Allows for Reprogramming of the Immune Compartment in Prostate Cancer
}

\author{
Muzamil Y. Want ${ }^{1}$, Ellen Karasik ${ }^{2}$, Bryan Gillard ${ }^{2}$, A. J. Robert McGray ${ }^{1}$ and Sebastiano Battaglia ${ }^{1,3, *}$ \\ 1 Department of Immunology, Division of Translational Immuno Oncology, \\ Roswell Park Comprehensive Cancer Center, Buffalo, NY 14263, USA; \\ muzamil.want@roswellpark.org (M.Y.W.); AJRobert.McGray@RoswellPark.org (A.J.R.M.) \\ 2 Department of Pharmacology and Therapeutics, Roswell Park Comprehensive Cancer Center, \\ Buffalo, NY 14263, USA; Ellen.Karasik@RoswellPark.org (E.K.); Bryan.Gillard@RoswellPark.org (B.G.) \\ 3 Department of Cancer Genetics and Genomics, Roswell Park Comprehensive Cancer Center, \\ Buffalo, NY 14263, USA \\ * Correspondence: sebastiano.battaglia@roswellpark.org
}

Citation: Want, M.Y.; Karasik, E.; Gillard, B.; McGray, A.J.R.; Battaglia, S. Inhibition of WHSC1 Allows for Reprogramming of the Immune Compartment in Prostate Cancer. Int. J. Mol. Sci. 2021, 22, 8742. https:// doi.org/10.3390/ijms22168742

Academic Editor: Alvaro Teijeira

Received: 4 July 2021

Accepted: 10 August 2021

Published: 14 August 2021

Publisher's Note: MDPI stays neutral with regard to jurisdictional claims in published maps and institutional affiliations.

Copyright: (c) 2021 by the authors. Licensee MDPI, Basel, Switzerland. This article is an open access article distributed under the terms and conditions of the Creative Commons Attribution (CC BY) license (https:/ / creativecommons.org/licenses/by/ $4.0 /)$.

\begin{abstract}
Immunotherapy initially demonstrated promising results in prostate cancer (PCa), but the modest or negative results of many recent trials highlight the need to overcome the poor immunogenicity of this cancer. The design of effective therapies for PCa is challenged by the limited understanding of the interface between PCa cells and the immune system in mediating therapeutic resistance. Prompted by our recent observations that elevated WHSC1, a histone methyltransferase known to promote progression of numerous cancers, can silence antigen processing and presentation in PCa, we performed a single-cell analysis of the intratumoral immune dynamics following in vivo pharmacological inhibition of WHSC1 in mice grafted with TRAMP C2 cells. We observed an increase in cytotoxic T and NK cells accumulation and effector function, accompanied by a parallel remodeling of the myeloid compartment, as well as abundant shifts in key ligand-receptor signaling pathways highlighting changes in cell-to-cell communication driven by WHSC1 inhibition. This comprehensive profiling of both immune and molecular changes during the course of WHSC1 blockade deepens our fundamental understanding of how anti-tumor immune responses develop and can be enhanced therapeutically for PCa.
\end{abstract}

Keywords: tumor microenvironment; prostate cancer; immunotherapy

\section{Introduction}

Modulating the immune landscape of prostate cancer (PCa) to promote anti-tumor immunity has gained enthusiasm following the initial clinical success of trials testing Provenge and Prostvac VF to stimulate immune responses against prostate acid phosphatase (PAP) and prostate specific antigen (PSA), respectively. While several studies have reported favorable clinical outcomes, especially in patients with therapy-induced immune infiltration, PCa tumors typically show only low-level immune cell infiltration in the tumor microenvironment (TME).

WHSC1 is a histone methyltransferase that targets histone 3 lysine 36 (H3K36) and, to a lesser extent, histone 4 lysine 20 (H4K20). Elevated WHSC1 expression correlates with worse prognosis in a number of cancers [1-7] due to its oncogenic role in promoting cell growth and metastases; however, the magnitude of the effect and mechanism(s) of action of WHSC1 remain poorly understood. In studies designed to understand the interplay between PCa cells and the immune system, we recently demonstrated that elevated levels of the WHSC1 enzyme limit lymphocyte infiltration in PCa tumors, reduce antigen processing and presentation, as well as repress local activation of immune pathways [8].

We previously reported that WHSC1 inhibition increases the frequency of intratumoral $\mathrm{CD}^{+} \mathrm{T}$ cells [8]; however, the changes associated with the overall immune composition 
of the TME following WHSC1 blockade remain unknown. Here, we broadly investigate the immunological changes in the TME in vivo following pharmacological inhibition of WHSC1and report a phenotypic shift in infiltrating immune cells that reflects both increased cytotoxic $\mathrm{T}$ cell activity and local modulation of diverse myeloid cell subsets present within the tumor. Lastly, using pathway analysis of changes resulting from WHSC1 inhibition, we propose a signaling circuitry that defines immune activation and favors a potent anti-tumor response.

\section{Results}

\subsection{Pharmacological Inhibition of WHSC1 Increases Survival and Immune Function In Vivo}

Immunocompetent C57B / 6 mice were grafted with TRAMP C2 cells [9] and treated with MCTP39 for 4 weeks. MCTP39 treatment resulted in tumor growth suppression, with an average reduction in tumor size of $66 \%$ in the treated group compared to the control (Figure 1A). While our previous findings demonstrated an increase in intratumoral lymphocytes in response to MCTP39 treatment [8], CD11 b ${ }^{+}$myeloid cells comprised the majority $(\sim 60 \%)$ of infiltrating immune cells in TRAMP C2 tumors regardless of treatment (Figure 1B). These results are consistent with previous reports describing high levels of monocytes/macrophages in the TME of prostate tumors [10,11] and melanoma [12]. To investigate whether MCTP39 treatment was impacting the myeloid cells on a global level in growing tumors, bulk RNA from resected tumors was processed and analyzed using the Nanostring immune myeloid panel gene set. Transcriptional changes following MCTP39 treatment showed increased expression of MHC genes (H2-DMb2, H2-Aa, and H2-Ab1) (Figure 1C, Supplementary File S1), consistent with our previous results [8], in addition to upregulation of Cd74, the invariant chain of MHC II [13] (Figure 1C). Chemokines involved in the recruitment of multiple immune cell subsets (Cxcr4, Cxcl13, Ccl22) were upregulated in parallel with the co-stimulatory molecules Icos and the checkpoint receptor Ctla4, suggesting complex immunological changes in the tumor microenvironment (TME) in response to treatment. (Figure 1C). Other upregulated genes were related to myeloid cell lineage commitment (Irf8) [14], myeloid/macrophage function (Il1a, Il1b, Osm), cellular mobility (Tspan7), as well as Cd38, which can be expressed by macrophages and correlates with improved outcome as observed in liver cancer [15], but can also function to breakdown ADP and suppress T cells' function [16] (Figure 1C). Interestingly, Pd-11 (Cd274) was also upregulated (Figure 1C), consistent with the induction of adaptive immune resistance mechanisms following local immune activation [17] and anti-tumor immunity (Figure 1C). Functional enrichment analysis, adjusted for the size of the Nanostring gene set, revealed that the top enriched pathways were associated with the activation of adaptive and innate immune responses in parallel with increased antigen processing and presentation (Figure 1D). Overall, these results point towards a parallel reshaping of the lymphoid and myeloid compartments following pharmacological inhibition of WHSC1 in vivo.

\subsection{WHSC1 Inhibition Alters the Infiltration of T Cells and Modulates DC Function}

To further investigate immunological changes resulting from WHSC1 inhibition, CD45+ cells were isolated from tumors after 4 weeks of treatment with MCTP39 and analyzed via flow cytometry. While the overall number of $\mathrm{CD}^{2} 5^{+} \mathrm{CD}^{+}$lymphocytes was constant across conditions (Figure S1A), MCTP39 treatment led to a decrease in total CD4 ${ }^{+}$ TILs, accompanied by a parallel increase in CD8 ${ }^{+}$TILs (Figure 1E). Within CD8 ${ }^{+} \mathrm{T}$ cells, we identified an increase in the frequency of PD $-1^{+} \mathrm{CD} 8^{+}$TIL following MCTP39 treatment (Figure $1 \mathrm{~F}$, upper panel). Additionally, within the $\mathrm{CD} 4^{+} \mathrm{T}$ cell compartment, we observed a decrease in $\mathrm{CD} 4{ }^{+} \mathrm{CD} 25^{+}$Tregs in the treatment group (Figure 1F, lower panel), although this was not statistically different. Lastly, we observed a significant increase in MHC-II on $\mathrm{CD}_{4} 5^{+} \mathrm{CD} 11 \mathrm{c}^{+} \mathrm{DCs}$ in treated mice compared to controls. (Figure 1G), consistent with increased localization of immunostimulatory DCs in the TME following treatment. The elevation in MHC-II and the increased $\mathrm{CD} 8^{+} \mathrm{T}$ cell infiltration are supported by the gene expression data from Nanostring (Figure 1C,D) and suggest an active reshaping of the 
immune compartment from immuno-suppressive to immuno-permissive, thus enhancing the anti-tumor functional activity of infiltrating immune cells.
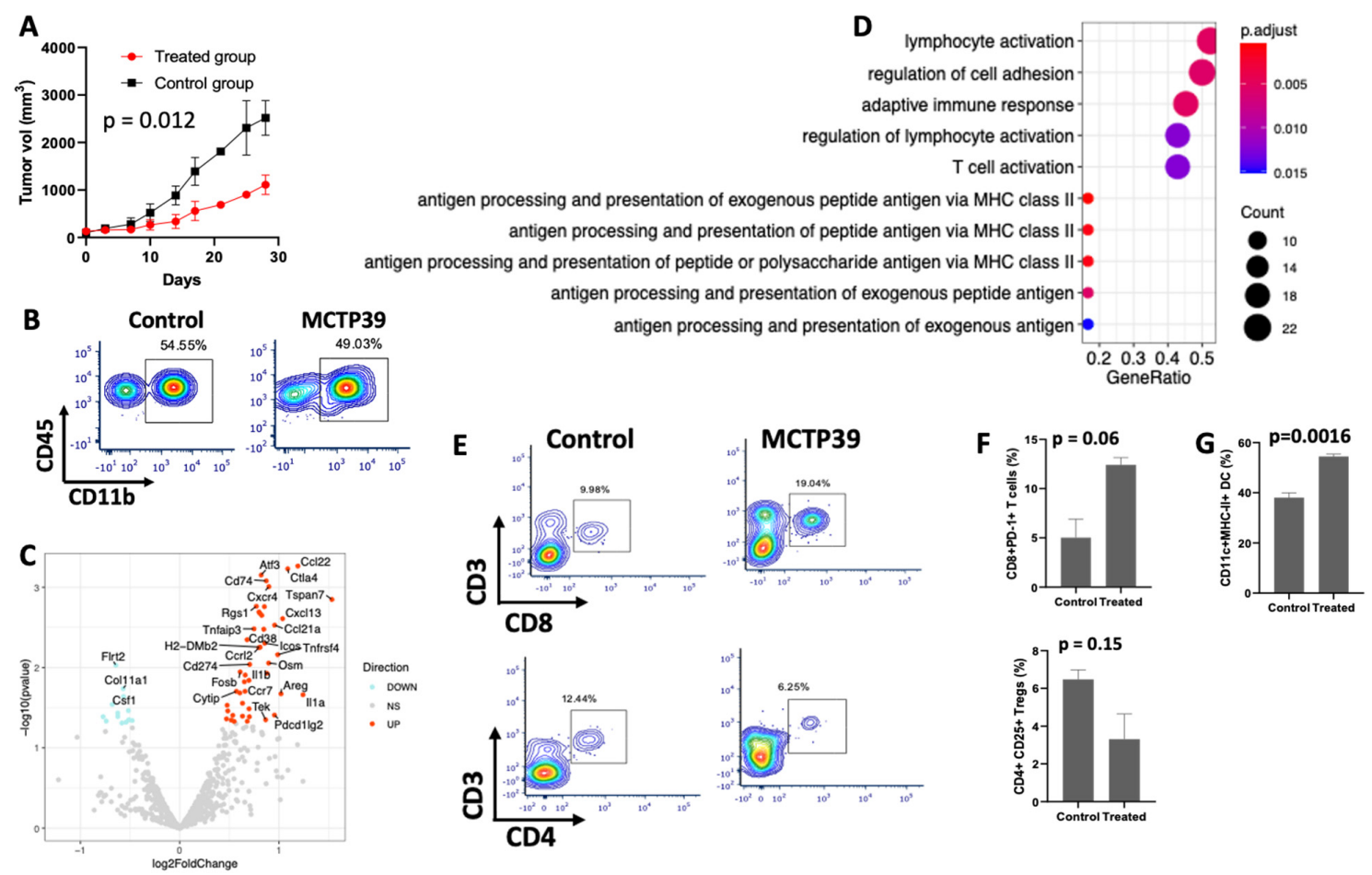

Figure 1. Effect of WHSC1 inhibition in vivo. (A) Tumor growth in MCTP39-treated mice. Tumor growth was measured over time in mice grafted subcutaneously with TRAMP C2 cells. Black and red lines indicate control and MCTP39-treated mice, respectively. Each time point reports the average tumor growth in at least two mice. (B) Intratumoral CD $45^{+} \mathrm{CD} 11 \mathrm{~b}^{+}$ cell abundance in tumors from control and mice treated with MCTP39. Percentage of gated cells over total number of cells is shown. (C) Volcano plot showing the results from differential gene expression analysis of the Nanostring data. Red and cyan dots indicate up- and downregulated genes, respectively. Note that not all gene names are shown to reduce visual crowding. (D) Functional enrichment analysis of the differentially expressed genes from Nanostring data shown in $\mathbf{C}$ using murine gene ontology signatures. (E) Flow cytometry analysis of $\mathrm{CD} 3^{+} \mathrm{CD} 8^{+}$and $\mathrm{CD} 3^{+} \mathrm{CD} 4^{+} \mathrm{T}$ cells in control (left) and treated (right) samples. (F) Quantification of PD-1+CD8 ${ }^{+} \mathrm{T}$ cells (top) and CD4 ${ }^{+} \mathrm{CD} 25^{+}$Tregs (bottom). (G) Quantification of $\mathrm{CD} 11 \mathrm{c}^{+} \mathrm{MHC}-\mathrm{II}^{+}$dendritic cells. Each bar represents the mean and SD of at least two biological replicates. $p$ values were calculated with Students' $t$ test.

\subsection{Heterogeneous Myeloid Populations Infiltrate Prostate Tumors}

Since treatment of tumor-bearing mice with MCTP39 affects intratumoral immune pathways globally [8] and alters multiple infiltrating immune cell subsets, we sought to investigate how the broader immune landscape of tumors was being impacted by MCTP39. To this end, we interrogated intratumoral $\mathrm{CD}^{+} 5^{+}$single cells from control and MCTP39treated mice using scRNASeq. Following QC, preprocessing, and removal of dead and low-quality cells, 3000 cells per condition were used for downstream analyses. Consistent with the results from flow cytometry, the majority of the $\mathrm{CD} 45^{+}$population comprised $\mathrm{CD}_{11 \mathrm{~b}^{+}}$myeloid cells, with limited infiltration by $\mathrm{CD}^{+} \mathrm{T}^{+}$lymphocytes (Figure $2 \mathrm{~A}$ ), and subsequent cluster analysis separated the lymphoid from the myeloid compartments (Figure S2).

In order to gain a more granular understanding of the immune populations infiltrating PCa tumors, the lymphocytic and myeloid compartments were further annotated. The myeloid populations span across nine closely aggregated clusters, with two clusters, 4 and 9 , spatially separated from the others (Figure 2B, Figure S2). The presence of closely related myeloid cells is consistent with the biology of myeloid cells, which exist on a spectrum of differentiation that, depending on the stimulus, can commit to different functional 
programs, including diverse DC lineages, or to M1/M2 polarization. We therefore utilized a panel of established markers (Supplementary File S2) and their corresponding gene expression patterns to annotate the identified populations to the correct clusters.

A
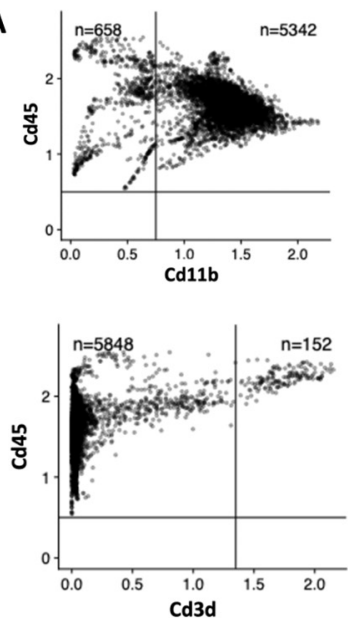

B

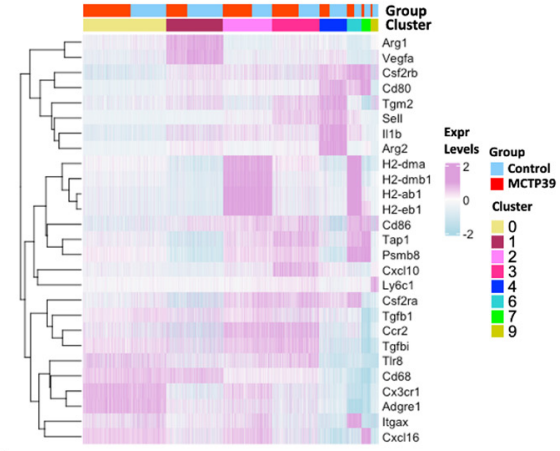

D

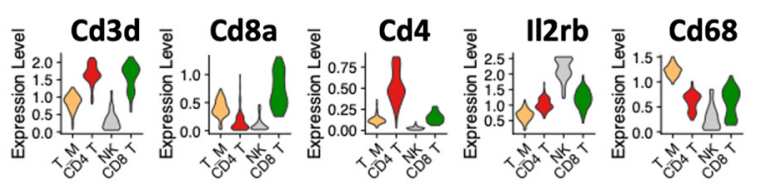

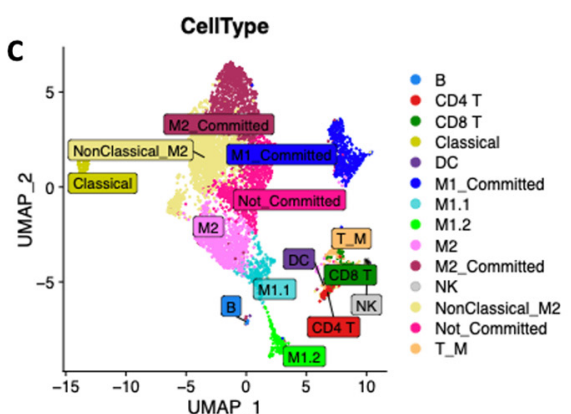
Figure 2. scRNASeq analysis of tumor-infiltrating immune cells. (A) Exploratory scatter plot showing the proportions of
$\mathrm{CD} 45^{+} \mathrm{CD} 11 \mathrm{~b}^{+}$myeloid cells (top) and $\mathrm{CD} 45^{+} \mathrm{CD}^{+}$lymphocytes (bottom) in the samples used for scRNASeq. (B) Expression pattens for the panel of genes used to classify myeloid cells. Purple and light blue cells indicate high and low expression, respectively. The annotation on top indicates the cluster assignments and the group (control, MCTP39). (C) UMAP representation of the final annotation for all the cell types identified. (D) Violin plots showing the expression of markers used to classify $\mathrm{CD}^{+}, \mathrm{CD}^{+}, \mathrm{NK}$, and T_M cells.

Given the overall abundance of myeloid cells in PCa tumors, myeloid cells were reclassified as shown in Figure 2B. Cluster 0 cells were positive for Cd68, Cd49/Adgre1, Cx3cr1, Cd11c/Itgax, and Cxcl16 and negative for Ccr2 and Cd62l/Sell, suggesting that these cells were non-classical monocytes committed to an M2 phenotype. Cluster 1 contained cells that expressed high levels of Cd68, VEGFa, and Arg1, in parallel with low levels of $\mathrm{Cd} 11 \mathrm{c} /$ Itgax and Cxcl16, pointing towards partially polarized M2 macrophages. Cluster 2 was positive for MHC class II, Cx3cr1, Cd49/Adgre1, Ccl5, and Cxcl16, representing M2 macrophages. Cluster 3 appeared to be a heterogeneous population with markers consistent with monocytes and macrophages, potentially indicating a non-committed population. Cells in cluster 4 were positive for Arg2, Il1b, Cd80, and Csf2rb, while still expressing Sell and were MHC II-negative, suggesting that they might be partially polarized M1 macrophages, as M1 macrophages can have low MHC expression, and were described as TAMs elsewhere [18]. Cluster 6 was positive for Csf2rb and Cd80, with high levels of MHC molecules, Cd11c/Itgax, Cd86, and detectable I11b, suggesting almost fully polarized M1 macrophages. Cluster 7 contained cells positive for Cd80, Csf2rb, Cd86, and the chemokines $\mathrm{Ccl} 5$ and $\mathrm{Cxcl16}$, with detectable MHC expression, suggesting a separate subset of polarized M1 macrophages. Cluster 8 had high levels of Cx3cr1, Cd49/Adgre1, and Tlr8, were negative for Cd86, and showed low levels of Cd68 and Cxcl16, suggesting non-classical monocytes committed to becoming M2 macrophages. Lastly, cluster 9 was positive for Ly6c1, with weak Csf2rb, Tgm2, and Cd86 expression, suggesting uncommitted classical monocytes.

Next, we profiled the lymphoid compartment. First, we classified the lymphocytic populations in clusters 5 and 10 , successfully separating $\mathrm{CD} 4^{+}$from $\mathrm{CD} 8^{+} \mathrm{T}$ cells and NK cells (Figure 2C). Interestingly, cluster 5 also included a rare population of macrophage with modest $\mathrm{Cd} 3$ expression, which we classified as $\mathrm{T}$ cell-like macrophage (T_M), which have been previously described as having a cytotoxic and pro-inflammatory role $[19,20]$. 
In our samples, this population expressed Tnf, the degranulation marker Lamp1/Cd107a, the chemokine CcrR5, and other M1 markers such as Cd68 and IL1B (Figure 2D).

\subsection{WHSC1 Inhibition Promotes Cytotoxic Functions}

To further understand the antitumor activity of the identified immune cell subsets following MCTP39 treatment, we next evaluated the expression of cytotoxic markers in treated and control tumors. There was an increase in the frequency of both CD8 ${ }^{+} \mathrm{T}$ cells and NK cells expressing cytotoxic markers including granzymes, Ifn- $\gamma$, and Lamp 1 (Figure 3A,B). As MCTP39 alone does not affect the proliferation of CD8 ${ }^{+} \mathrm{T}$ or the levels of IFN- $\gamma$ and TNF- $\alpha$ production when T cells are simulated in vitro (Figure S1B), this suggests that the observed activation of $\mathrm{CD}^{+} \mathrm{T}$ cells in vivo was not due to the direct activity of MCTP39. In parallel, we observed a modest reduction in the frequency of Il2 $\mathrm{ra}^{+} \mathrm{Foxp}^{+}$Treg following MCTP39 treatment (Figure 3A), consistent with the initial flow cytometry results. Interestingly, this was accompanied by a significant decrease in the frequency of $\mathrm{CD}^{+} \mathrm{T}$ cells expressing the exhaustion markers Cd244, Btla/Cd272, and Cd160 (Figure 3A), suggesting reinvigoration and/or prolonged functionality of CD8 ${ }^{+}$ $\mathrm{T}$ cells following treatment with MCTP39. $\mathrm{CD} 4^{+} \mathrm{T}$ cells and T_M cells also showed an increase in the degranulation marker Cd107a/Lamp1, Gzmk, and Ccr5 (Figure 3B), supporting the establishment of a pro-inflammatory TME following MCTP39 treatment. The complementary cytotoxic functions of $\mathrm{CD} 8^{+} \mathrm{T}$ cells and NK cells were investigated further by evaluating the coexpression of cytotoxic makers in these two cell types. NK cells showed a positive coexpression pattern for Cd69, Tnf, Ifng, Gmzb, and Prf1, with a separate pattern that included Gzmk, Lamp1, and Pdcd1 (PD-1) (Figure 3B,C). CD8 ${ }^{+} \mathrm{T}$ cells had a core pattern represented by Pdcd1, Gzmk, Gzmb, Ifn- $\gamma$, Prf1, with Lamp1 and Ccr5 representing a separate coexpression cluster (Figure 3B,C), suggesting that NK and $\mathrm{CD}^{+} \mathrm{T}$ cells possessed complementary, yet partially diverse, cytotoxic profiles. Overall, these results suggest that pharmacological inhibition of WHSC1 reshaped the lymphoid compartment of PCa towards a more immunopermissive and cytotoxic phenotype.

\subsection{Inhibition of WHC1 Functionally Reprograms the Myeloid and Lymphoid Compartments}

To better understand the changes in the myeloid compartment following treatment with MCTP39, we evaluated the frequency of activated M1 macrophages expressing Ccr5 and the frequency of immunosuppressive M2 macrophages positive for Arg1. In line with improved T cell activity and local inflammation, MCTP39 treatment led to a higher frequency of pro-inflammatory M1 cells and a corresponding decrease in Arg1-expressing M2 macrophages (Figure 3D). Interestingly, the T_M population expressing pro-inflammatory markers such as Gzmk, Ifng, and Ccr5 was increased in the treated group (Figure 3D), suggesting a global reprogramming of the myeloid compartment that favored a proinflammatory phenotype.

To further profile the transcriptional changes occurring after WHSC1 inhibition and the accompanying impact on intratumoral immunological functions, we performed differential gene expression analysis followed by functional enrichment analysis using the cell types identified above (Figure 4). In order to add valuable biological interpretation to the effect of MCTP39 in vivo, we used GSVA analysis to score pathway activity and the corresponding changes in each cell type. Following WHSC1 inhibition, clusters containing M1 and M2 macrophages had elevated expression of genes associated with chemokine activity and immune response. Conversely, M2_committed cells demonstrated an overall reduction in cytokine signaling, antigen presentation, and chemotaxis. Not committed cells appeared to increase the expression of genes associated with immune pathways, and DCs increased their ability to promote NK cells chemotaxis. $\mathrm{CD} 8^{+} \mathrm{T}$ cells revealed a strong upregulation of chemotaxis, migration, and immune response, in contrast to $\mathrm{CD} 4^{+} \mathrm{T}$ cells which showed a downregulation of genes involved in chemotaxis and immune response (Figure 4). Overall, these results suggest that inhibition of WHSC1 in vivo not only impacted lymphocyte function, but also led to an efficient reprogramming of the myeloid compartment, increasing 
antigen processing and presentation and limiting immunosuppressive transcriptional programs from M2 macrophages.
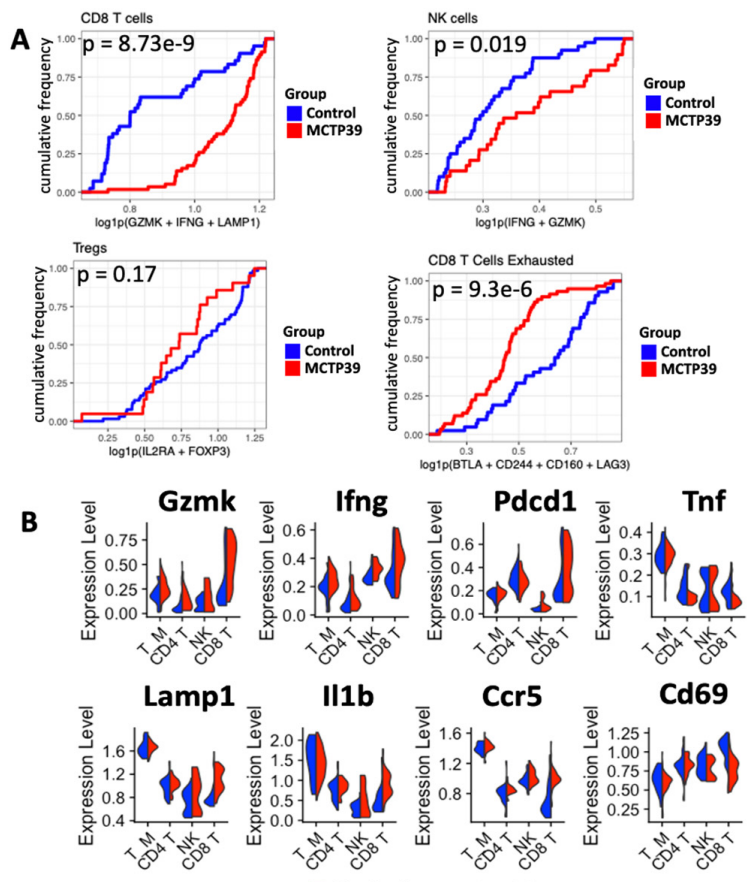

- Control = MCTP39
D
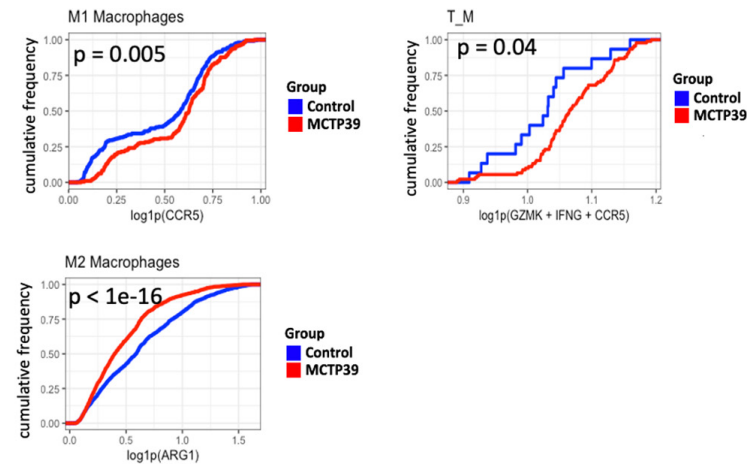

C

Figure 3. Cell population changes following WHSC1 inhibition. (A) Cumulative frequency of lymphocytic populations in control mice (blue) and MCTP39-treated mice (red). Population frequency (0 to 1 ) is shown on the y axis, expression levels of the markers in the axis name is shown on the $x$ axis. Significance was calculated using the Kolmogorov-Smirnov test, with $\mathrm{p}$ values shown in the figure. (B) Expression levels of the markers used to classify activated lymphocytes. Each violin plot is split for the control group (blue) and the MCTP39-treated group (red). (C) Correlation network analysis of the cytotoxic markers expressed in NK (left) and CD8 ${ }^{+} \mathrm{T}$ cells (right). (D) Cumulative frequency of myeloid populations in the control (blue) and MCTP39-treated samples (red). Significance was calculated using the Kolmogorov-Smirnov test, with $p$ values shown in the figure.

\subsection{Ligand-Receptor Networks Reveal Rewiring of the Immune Circuitry in Response to Inhibition of WHSC1}

While functional enrichment analysis revealed the upregulation of immune pathways following MCTP39 treatment, cell signaling events brought about through ligand-receptor interactions ultimately determine cellular response. In the attempt to profile the changes governing anti-tumor immune responses in the treated group, we compiled a list of ligand-receptor pairs [21] for chemokines and cytokine expressed within the myeloid and lymphoid compartments. We then scored each ligand-receptor interaction and compared the scores between treated and untreated samples to identify potential changes in proinflammatory signals elicited by MCTP39. The results separated cellular stimuli for CD8 ${ }^{+}$ $\mathrm{T}$ cells, $\mathrm{NK}$, and $\mathrm{CD}^{+} \mathrm{T}$ cells and defined three main clusters of signaling driven by $\mathrm{Ccl} 2$, Ccl12, Cd74, Gnai2, and Hmgp1 (C1), by Ifn- $\gamma$, Jak1, and Ccl5 (C2), and by Ccl3, Ccl4, and $\mathrm{Ccl} 7$ (C3). As shown in Figure 5A, signaling from $\mathrm{C} 1$ appeared to target mostly CD8 ${ }^{+} \mathrm{T}$ cells and $\mathrm{B}$ cells, independently of the cell type producing the ligand. Conversely, signaling from $\mathrm{C} 2$ appeared to originate from DCs and targeted multiple cell types (Figure 5A). Similar to C1, C 3 broadly targets lymphocyte subsets through interactions with diverse myeloid cell subtypes. When key receptors involved in these signaling pathways were compared using gene expression, the levels of Cxcr4 and Ccr2 (C1) were elevated in CD8+ T cells and B cells, which also showed increased levels of Ifn- $\gamma$ receptor and Ccr5 (Figure 5B). Similarly, Jak1, Ifn- $\gamma$, and Ccl5 expression levels (C2) were elevated in multiple myeloid cell subsets following MCTP39 treatment. In contrast, genes associated with cluster C3 did not show 
remarkable changes across individual myeloid cell subsets following MCTP39 treatment, suggesting that changes associated with this cluster may be the result of the collective signaling events occurring through multiple cellular interactions. To this end, since a single ligand can bind to multiple receptors, and vice versa, we performed a network analysis with clustering of the ligand-receptor pairs mentioned above and identified 12 clusters by which signals were propagated, with the largest group containing $\mathrm{Cxcl} / \mathrm{Ccl}$ cytokines (Figure 5C). Overall, these results suggest that changes in the immune circuitry following WHSC1 inhibition in vivo were driven by a rewiring of the signaling from macrophage subsets and DCs, to ultimately elicit anti-tumor effects from T, NK, and B cells.

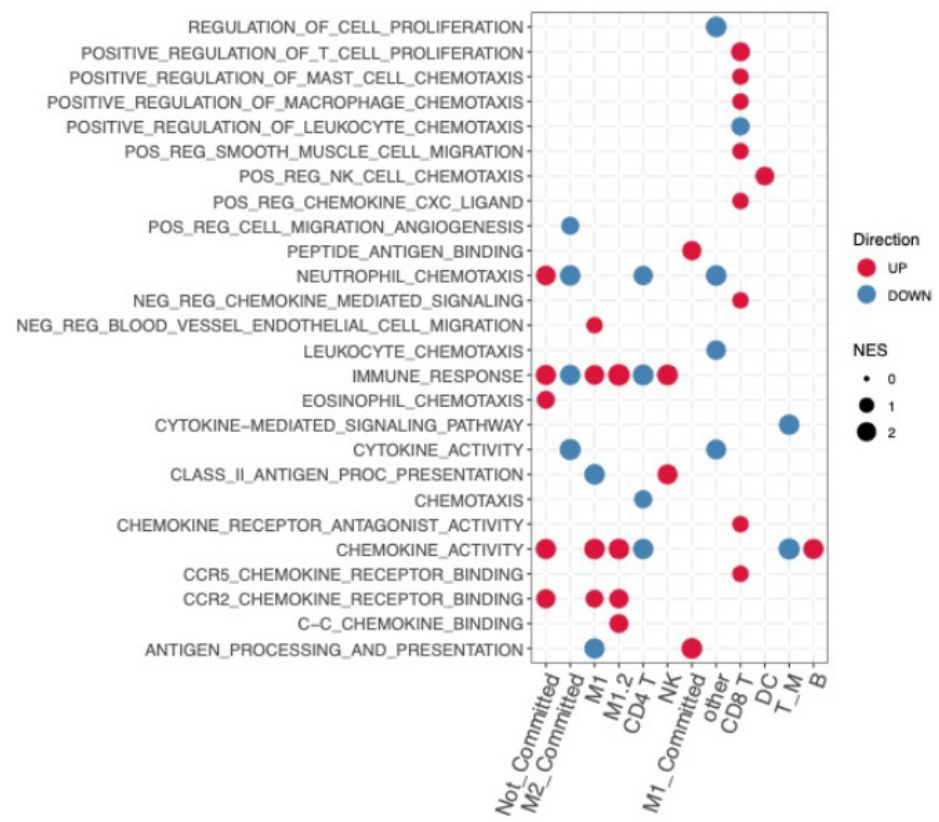

Figure 4. Gene set variation analysis. Results from GSVA analysis using the top up- and downregulated genes for each cell type/cluster. Red (positive) and blue (negative) dots indicate significant pathway normalized enrichment scores (NES), obtained by comparing the control to MCTP39-treated samples. Each cell type (x axis) was analyzed individually.
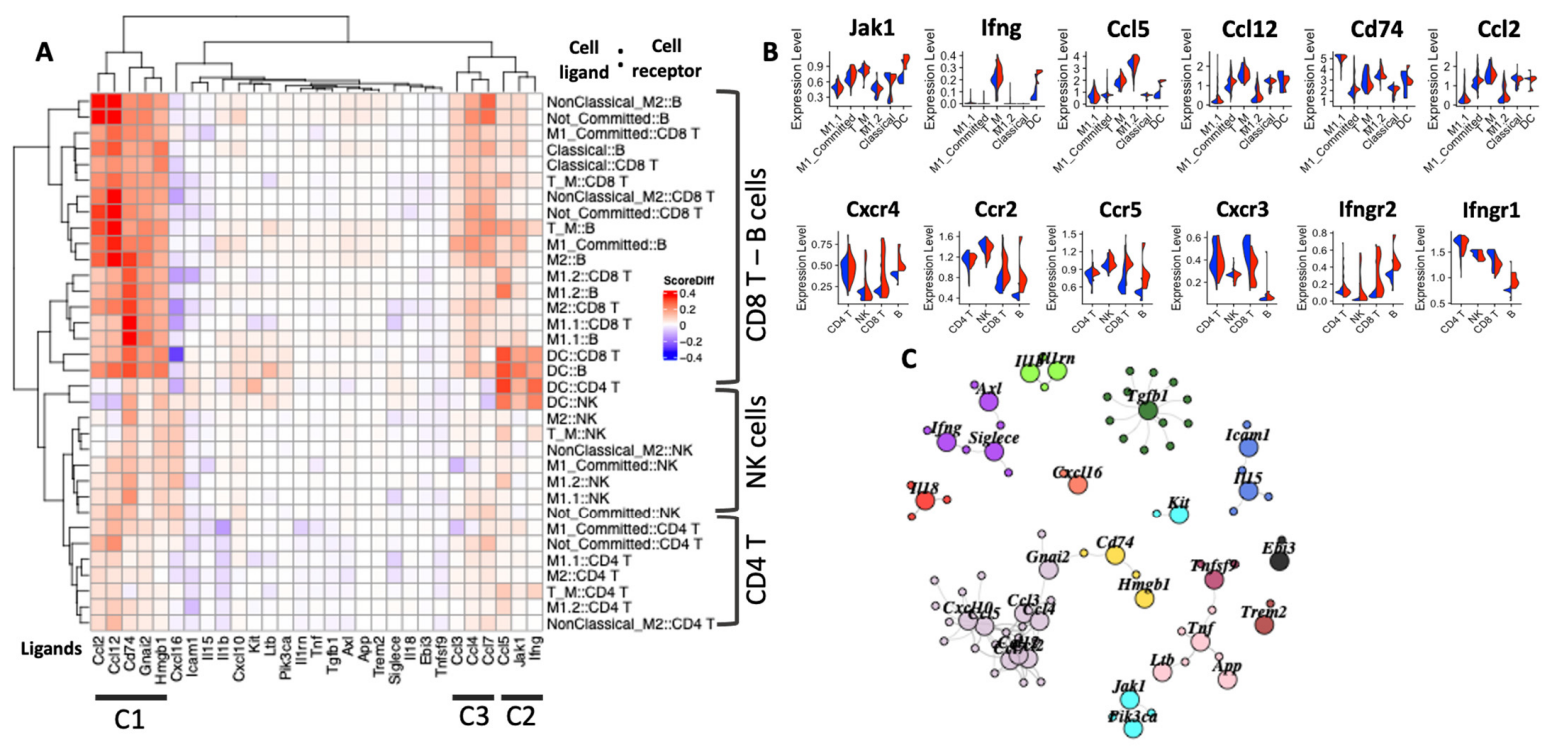

Figure 5. Ligand-receptor analysis. (A) Heatmap representing the difference in score between the control and MCTP39treated samples. Red and blue cells denote that scores are higher or lower, respectively, following MCTP39 treatment and indicate a potential increase in cell-to-cell communication via a specific ligand-receptor interaction. Ligands are assumed to 
be produced by myeloid cells (see previous results), and the top changing ligands are listed at the bottom. The row names indicate the cell pair considered. The most represented receptor-expressing cell types are highlighted on the right side. (B) Violin plots showing the expression levels of the ligand and receptors for the top results shown in the heatmap. Cell types are shown on the $x$ axis. (C) Cluster analysis of the ligand-receptor groups representing an overview of the multiple ligand -receptor interactions possible. Colors indicate different clusters.

\section{Discussion}

We recently demonstrated that WHSC1 inhibition potently increases antigen processing and presentation via an elegant epigenetic remodeling of prostate cancer cells that increases MHC expression and antigen presentation, accompanied by an increase in tumor-infiltrating $\mathrm{CD} 8^{+} \mathrm{T}$ cells [8]. Interestingly, we also observed that when tumors were grafted in immunodeficient NSG mice, no tumor growth inhibition was observed [8], suggesting that at least part of the anti-tumor effect of MCTP39 was mediated through the activity of a functional immune system. While recognizing that both mouse models were grafted subcutaneously (SQ), it is well established that SQ tumors are still subject to the immune-driven anti-tumor effect in numerous cancer indications $[8,12,22-27]$ and include a rich and heterogeneous immune compartment reshaped by therapeutic interventions. For these studies, we used the syngeneic prostate cancer cell line TRAMP C2 [9] that can be grafted in immunocompetent mice, thus permitting tumor-infiltrating immune cells to be broadly profiled in response to therapy.

Previous studies employing single-cell analyses identified large myeloid and lymphoid infiltrates in the prostate tumors of 13 patients [28], suggesting an interconnected cellular network between tumors and the immune system that may define disease progression. However, on the therapeutic side, there is still limited knowledge regarding the immune signaling events that accompany prostate cancer regression following effective treatment.

When evaluating the expression of a focused panel of immune genes from bulk data, we identified a significant enrichment in antigen presentation pathways, lymphocyte activation, and migration. Among the most upregulated genes, we saw the ligands Cxcl13, Ccl21a, and Ccl22 and the chemokine receptors Cxcr4 and Ccr7. CCL22 is a homeostatic cytokine that can be produced in response to inflammation and acts through its receptor CCR4 to control immune activation in the lymph node [29,30]. The CCL21/CCR7 axis has a dual role, since it can both regulate the homing of immune cells to the lymph node to prime and activate T cells, B cells, and dendritic cells [31] and be involved in a metastatic tumor phenotype by promoting cancer cells migration [32,33]. In parallel to these functions, CXCL13 plays a key role in promoting immune infiltration in the tumor via binding to CXCR5 and controlling tumor behavior by binding to receptors on the tumor surface [34]. While overall pathway analysis suggested that treatment with MCTP39 enriched gene signatures related to immune functions, immune cell recruitment, and antigen processing and presentation, the origin of the signal and the location of the receptor can determine whether the resulting signaling cascade will lead to a pro-tumorigenic or anti-tumor response. Single cell RNASeq analyses revealed a large infiltrating myeloid cell component, consistent with previous studies of $\mathrm{CD}^{+} 5^{+}$cells infiltrating prostate tumors $[10,11]$, and suggested that improving the function of $\mathrm{T}$ cells within prostate cancer will necessitate successfully reprogramming the more abundant myeloid cells to promote local inflammation and anti-tumor immunity [35]. Based on our data and the broad and pleiotropic effects of MCTP39 on myeloid cell reprogramming, we propose that MCTP39 has previously underappreciated activity in targeting and modulating multiple simultaneous attributes of myeloid cell biology, which warrants additional investigation.

To maximize the anti-tumor immune response, the presence and activation of cytotoxic cells is required. Mice that were treated with MCTP39 had a higher frequency of cytotoxic $\mathrm{CD}^{+} \mathrm{T}$ cells and NK cells, positive for Granzyme K, Ifn- $\gamma$, and Lamp1/Cd107a. The latter plays a key role in forming cytotoxic granules to be released upon antigen recognition, potentially indicating an ongoing anti-tumor response. The expression of Pdcd1/Cd279/Pd-1 
was also increased in CD8 ${ }^{+} \mathrm{T}$ cells, and while elevated PD- 1 is a marker for exhausted $\mathrm{CD} 8^{+} \mathrm{T}$ cells, it also defines tumor- and neoantigen-specific $\mathrm{T}$ cells. In this case, we also observed a significant reduction in the frequency of $\mathrm{CD} 8^{+} \mathrm{T}$ cells expressing exhaustion markers including Lag3 [36-38], Btla [39], Cd244 [40], and Cd160 [41,42], while coexpressing granzymes and IFN- $\gamma$, suggesting the presence of activated, rather than exhausted, $\mathrm{T}$ cells. Furthermore, MCTP39 did not appear to play a direct role in enhancing CD8 ${ }^{+} \mathrm{T}$ cells activation, supporting the hypothesis that the observed increase in $\mathrm{T}$ cell activation was driven by tumor antigens recognition in addition to immunostimulatory cues in the TME that were driven by MCTP39 treatment. Additionally, it is possible that the effects of MCTP39 on T cells may be unique, in that MCTP39 is able to directly diminish T cell exhaustion, although whether this effect is sustained over time is currently unknown and may necessitate blockade of key inhibitory pathways to produce durable $\mathrm{T}$ cell responses. In light of this, further efforts to bolster T cell activity in the tumor following MCTP39 may benefit from either combination therapy using checkpoint blockade or through targeting $\mathrm{T}$ cell co-stimulatory pathways. Combination therapies usinganti-PD1/PD-L1 could be particularly beneficial, as MCTP39 appears to enhance anti-tumor immunity in vivo, and WHSC1 knockdown in vitro downregulates PD-L1 expression in PCa cancer cells [8]. Since the expression of CD274/PD-L1 by immune cells was maintained following MCTP39 treatment (with the exception of a modest reduction in M1_Committed macrophages expressing CD274/PD-L1 (Figure S3)), combination with anti-PD-L1 therapy could help to reduce the inhibitory signals arising from tumor-infiltrating immune cells and enhance the duration of anti-tumor immunity. Interestingly, recent studies indicate that NK cells appear to benefit from checkpoint blockade therapy, with NK cell responses having a fundamental role in generating maximal anti-tumor immunity [43]. In our system, the pattern of expression of cytotoxic markers in $\mathrm{CD}^{+} \mathrm{T}$ cells and NK cells following treatment indicates that these cell subsets have complementary but different polyfunctional phenotypes, suggesting that a combination of WHSC1 inhibition with checkpoint blockade could optimally activate both cell types, resulting in a potent anti-tumor response. Lastly, because of the increased levels of antigen presentation after MCTP39 treatment [8], we speculate that combination with WHSC1 inhibition could benefit PCa patients who receive vaccines (such as Provenge or Prostvac VF) by preferentially augmenting antigen processing and presentation following vaccination to bolster anti-tumor immunity.

While a high abundance of intratumoral myeloid cells can be associated with an immunosuppressive TME, macrophages and classical monocytes can promote a sustained inflammatory response and favor $\mathrm{T}$ cell homing to the tumor. In our model, inhibition of WHSC1 altered the transcriptional programs of M1 and M2 macrophages, upregulating genes in both antigen processing and presentation and leukocytes migration pathways. These results are in line with the increased frequency of cytotoxic immune cells in the treated group and suggest that myeloid cell reprogramming through MCT39 actively enhances the anti-tumor immune response.

Due to the coordinated action of chemokine ligands and receptors, immune cells are able to recruit cytotoxic $\mathrm{T}$ and NK cells to the target sites [44,45] or, conversely, they can ameliorate an ongoing inflammation process. We surveyed the ligand-receptor pairs for each classified cell type in an attempt to profile the mechanism(s) by which autocrine and paracrine signaling from cytokines and chemokines can rewire the immune behavior in tumors. For example, Nanostring analysis revealed a higher expression of Cd74. CD74, also named MHC II invariant chain [13], acts as chaperone for class II MHC antigen presentation and collaborates with MHC II to present surface antigens to the immune system [46]. In parallel, it is also known to bind to Cxcr4 in monocytes and T cells [47] and to Cxcr2 to promote leukocytes recruitment [48]. Our data indicate increased signaling in macrophages and DCs that promotes CD8+ T cell recruitment via Cxcr2/Cxcr4. These results are consistent with both higher $\mathrm{CD} 8^{+} \mathrm{T}$ cell infiltration and MHC expression on DCs as measured by flow cytometry, suggesting a potential molecular mechanism by which WHSC1 inhibition alters paracrine signaling in myeloid cells, promoting higher $\mathrm{T}$ cell 
infiltration in the tumor and ultimately establishing an immuno-stimulatory TME. The Ccr5 receptor is uniquely expressed on activated $T$ cells $[49,50]$ and was upregulated in the MCTP39-treated group, in parallel with an upregulation of Cc15 (a ligand for Ccr5) in DCs, M1, and T_M macrophages. Ccr5 was shown to promote T cell activation in concert with Cxcr4 [50], which can act as receptor for HMGB1 [51], Cxcl12 [52,53], and Cd74 [54]. While computational predictions suggest that complementary pro-inflammatory signals converge to establish a potent anti-tumor immune response, further experimental validation of the changes in cytokine and chemokine levels in each cell type would allow for a more precise interpretation of MCTP39 activity in the TME. The use of multiple prostate cancer models paired with toxicity analyses would further help to expand our current understanding of the safety and clinical applicability of the pharmacological inhibition of WHSC1, thus allowing for these findings to be translated as a clinically actionable treatment approach.

In conclusion, we present a detailed study that addresses the role of WHSC1 in altering anti-tumor cytotoxicity by rewiring the chemokine and cytokine signaling governing the communication between myeloid and lymphoid cells that infiltrate tumors. Due to the vast array of pro-tumorigenic functions shared by WHSC1 across cancer types [1-7], future studies that extend this approach to other tumor indications will reveal whether WHSC1 has a pan- or multi-cancer immuno-modulatory role. The downstream consequences of these findings have direct therapeutic implications, where cancer patients can be stratified based on WHSC1 expression to identify those that would benefit from WHSC1 inhibition as a complementary approach to immunotherapy.

\section{Methods}

Mice and sample collection: Immunocompetent C57BL/ 6 mice were used to interrogate immunological changes across conditions. Male mice (9-12 weeks old) were obtained from breeder colonies at the Center for Immunotherapy at Roswell Park and injected with $1 \times 10^{6}$ cells TRAMP C-2 cells prepared in $100 \mu \mathrm{L}$ PBS subcutaneously into the right flank using a $27 \mathrm{G}$ needle. Tumor volume was monitored after every 2-3 days with an electronic caliper and calculated as $V=\left(W^{2} \times L\right) / 2$, where $V$ is tumor volume, $W$ is tumor width, and $L$ is tumor length. When tumors reached $50-100 \mathrm{~mm}^{3}$, mice were randomly divided into two groups and treated with either MCTP-39 (10 mg/ $\mathrm{kg} 5 \times /$ week/4weeks, IP) or vehicle control. Mice were euthanized after 4 weeks of treatment. Statistical difference between the two growth curves was calculated via permutation test with 10,000 simulations using the compare GrowthCurves function of the statmod R package [55].

Cell sorting: Tumors from treated and control groups were harvested, cut into 1-2 mm pieces, and digested in collagenase $(1 \mathrm{mg} / \mathrm{mL})$ (Millipore Sigma, St. Louis, MO, USA) and DNAase $1\left(0.5 \mathrm{mg} / \mathrm{mL}\right.$, Roche, Basel, Switzerland) for $45 \mathrm{~min}$ at $37^{\circ} \mathrm{C}$ with constant shaking. The digested tissues were passed through $40 \mu \mathrm{m}$ cell strainers gently and centrifugated at $400 \mathrm{~g}$ for $5 \mathrm{~min}$. The supernatant was discarded, and cell pellets were incubated with $1 \mathrm{~mL}$ of ACK lysis buffer (Gibco, Life Technologies, Grand Island, NY, USA) for $5 \mathrm{~min}$ at RT. The cells were further washed with FACS buffer $2 X$ and stained with zombie aqua for 15 min at RT, followed by staining with AF700 anti-mouse CD45 antibody (clone 30-F11, Biolegend, San Diego, CA, USA) for 20 min at $4{ }^{\circ} \mathrm{C}$. The cells were further washed $2 \mathrm{X}$ with FACS buffer prior to being sorted using a BD FACSAria I cell sorter. The collected cells were gated on live CD45+ fraction and were used for single-cell RNA seq by 10X Genomics (Plesanton, CA, USA).

Flow cytometry analysis: For flowcytometry, single-cell suspensions from tumors were prepared as noted above and stained with zombie aqua for $15 \mathrm{~min}$ at RT followed by staining with Ax700 anti-CD45 (clone 30-F11), PerCP/Cy5.5 anti-CD8a (clone 53-6.7), FITC anti-CD3 (clone 145-2C11), APC /Fire 750 anti-CD4 (clone GK 1.5), BV605-anti-CD25 (clone PC61), BV605 anti-PD-1 (29F.IA12), BV785 anti-CD11b (clone M1/70), BV605 anti-CD11c (clone N418), PE anti-MHC-II (clone M5/114.15.2) for 20 min at $4{ }^{\circ} \mathrm{C}$. All antibodies were procured from Biolegend, USA, unless mentioned otherwise. After staining, cells were washed and fixed with fixation buffer (Biolegend, San Diego, CA, USA) for $15 \mathrm{~min}$ at 
$4{ }^{\circ} \mathrm{C}$ followed by washing $2 \times$ with FACS buffer prior to flow cytometry analysis. For in vitro $C D 8+T$ cell proliferation and functional assays, $C D 8+T$ cells were isolated from the spleen and lymph nodes of naive C57BL6/mice using an untouched CD8+ T cell isolation kit (Life Technologies, USA). In total, $2.5 \times 10^{6}$ cells in complete RPMI medium were seeded per well in a 24-well plate and incubated with or without $2 \mu \mathrm{M}$ MCTP-39. After $4 \mathrm{~h}$ of incubation, cells were washed with medium to remove MCTP-39 and were labelled with CFSE for $10 \mathrm{~min}$ at RT. The cells were washed to remove uninternalized CFSE and resuspended at $0.1 \times 10^{6}$ cells per well in $100 \mu \mathrm{L}$ of RPMI medium supplemented with MACSibead particles conjugated to $\alpha \mathrm{CD} 3 / \mathrm{CD} 28$ mouse beads (1:1 bead-to-cell ratio, Militinyi Biotech), 0.01M $\beta$-mercaptoethanol (Sigma Aldrich, USA), and IL-2 (100 U/mL, Peprotech), and $\mathrm{T}$ cells were incubated for 4 days at $37{ }^{\circ} \mathrm{C}, 5 \% \mathrm{CO}_{2}$. After incubation, the cells were washed with 1 X PBS and stained with zombie aqua followed by anti-CD8 antibody before being analyzed by flow cytometry. For CD8+ T cell functional assays, after 4 days of incubation with MACSibead particles conjugated to $\alpha \mathrm{CD} 3 / \mathrm{CD} 28$ mouse beads, the cells were centrifuged, and $100 \mu \mathrm{L}$ of medium containing a cell activation cocktail with brefeldin A (Biolegend, San Diego, CA, USA) was added; incubation was carried out for $6 \mathrm{~h}$. After incubation, the cells were washed with PBS twice and stained with zombie aqua followed by staining with PerCP anti-CD8 (clone 53-6.7)). For intracellular staining, cells were fixed using fixation buffer (Biolegend, San Diego, CA, USA), permeabilized with intracellular staining perm wash buffer (Biolegend, San Diego, CA, USA), and stained with APC anti-IFN- $\gamma$ (clone XMG1.2) and PE-anti TNF- $\alpha$ (clone 17B5) for 30 min at RT followed by flow cytometry analysis using a Fortessa flow cytometer. All flow cytometry data were analyzed using FCS express Edition 7 (De Novo Software, Pasadena, CA, USA).

scRNASeq analysis: Transcripts from sorted CD45+ cells were quantified using the $10 \times$ Genomics scRNASeq Chromium Next GEM Single Cell 3' Kits v3.1. Raw reads were initially mapped with $10 \times$ Cell Ranges prior to importing the results in $\mathrm{R}$ for further processing and downstream analyses with Seurat [56]. Briefly, after importing the raw data, cells were filtered based on number of features $(200<x<4000)$ and percentage of mitochondrial gene expression $(x<3)$. Immune populations were identified using Seurat's multimodal analysis pipeline followed by manual annotation, and gene expression was imputed using Rmagic [57]. Immune population frequency across treatment groups was calculated using $\mathrm{R}^{\prime}$ s empirical cumulative distribution function (ecdf) on $\log 1 \mathrm{p}$-transformed data, and the Kolmogorov Smirnov's test was used to test the difference between the two cumulative distributions at a significance level of 0.05 .

The list of genes used to classify cell types is provided in Supplementary File S2.

Differential gene expression was performed with Seurat's FindMarkers function using the MAST algorithm, a minimum pct of 0.25 , and a minimum $\operatorname{logFC}$ of 0.25 . Gene set enrichment analysis was performed using the fgsea package [58] with the ranked top 100 up- and downregulated genes for each cluster. Pathway information for mouse was downloaded from MSigDB and includes gene signatures from GO, Panther, WikiPathways, Inoh, Netpath, and Biocarta.

Ligand-receptor analysis: data from ligand-receptor pairs were obtained from $\mathrm{Ku}-$ mar et al. [21]. In our data, ligands were selected from the above based on a cutoff of $p<0.05$ from differential gene expression analysis. The ligand-receptor score was calculated as the product of the mean expression of the ligand in the selected cell type and the mean expression of the receptor in the target cell line, as described by others [21]. This was done separately for the MCTP39 and control groups. The difference of the two scores was used to infer increased/reduced signaling through a ligand-receptor pair for each cell type combination. Network analysis of the ligand-receptor pairs was done using the igraph package in R [59], and communities were identified via clustering analysis using the cluster_label_prop function in igraph.

Nanostring data analysis: Tumors from mice grafted with TRAMP C2 cells were harvested after 4 weeks of treatment with MCTP39. Nucleic acid extraction and sample preparation for the Nanostring myeloid panel array were completed at the Roswell Park 
Genomics Shared Resources (GSR) following the manufacturer's guidelines. Raw data were processed in $\mathrm{R}$ using the pipeline described by Bhattacharya et al. [60], with downstream differential gene expression analysis performed using DESeq2 [61] at a significance level of $p<0.05$. Functional enrichment analysis was performed using the DOSE Bioconductor package [62].

Supplementary Materials: The following are available online at https:/ /www.mdpi.com/article/10 $.3390 / \mathrm{ijms} 22168742 / \mathrm{s} 1$.

Author Contributions: M.Y.W. performed the in vitro experiments; M.Y.W., E.K., and B.G. performed the in vivo experiments; M.Y.W. and A.J.R.M. analyzed the immunological data; S.B. conceived and designed the project and performed the bioinformatics analyses; S.B. and A.J.R.M. defined the layout of the manuscript; S.B., A.J.R.M., and M.Y.W. wrote the manuscript. All authors have read and agreed to the published version of the manuscript.

Funding: S.B.- Roswell Park Alliance Foundation and Roswell Park Startup Funds. This work was also supported by Roswell Park Comprehensive Cancer Center and National Cancer Institute (NCI) grant P30CA016056 involving the use of the Genomic Shared Resources, Immune Analysis Shared Resources and the Gene Modulation Shared Resources.

Institutional Review Board Statement: The study was conducted according to the guidelines of the IACUC Institutional Review Board of Roswell Park Comprehensive Cancer Center (protocol \# 1377M).

Informed Consent Statement: Not applicable.

Data Availability Statement: Sequencing data are available on GEO.

Acknowledgments: The authors want to thank P. Kalinski, S. Abrahams, and A. Hutson for the feedback and comments about the manuscript.

Conflicts of Interest: The authors declare no conflict of interest.

\section{Abbreviations}

$\begin{array}{ll}\text { DC } & \text { Dendritic Cells } \\ \text { GSVA } & \text { Gene Set Variation Analysis } \\ \text { IFNg } & \text { Interferon gamma } \\ \text { MHC } & \text { Major Histocompatibility Complex } \\ \text { NK } & \text { Natural Killer cells } \\ \text { PCa } & \text { Prostate Cancer } \\ \text { QC } & \text { Quality Control } \\ \text { scRNASeq } & \text { Single-Cell RNA Sequencing } \\ \text { T_M } & \text { T cell-like Macrophages } \\ \text { TIL } & \text { Tumor-Infiltrating Lymphocypes } \\ \text { TME } & \text { Tumor MicroEnvironment } \\ \text { TRAMP } & \text { Transgenic Adenocarcinoma of the Mouse Prostate }\end{array}$

\section{References}

1. Li, N.; Xue, W.; Yuan, H.; Dong, B.; Ding, Y.; Liu, Y.; Jiang, M.; Kan, S.; Sun, T.; Ren, J.; et al. AKT-mediated stabilization of histone methyltransferase WHSC1 promotes prostate cancer metastasis. J. Clin. Investig. 2017, 127, 1284-1302. [CrossRef] [PubMed]

2. Garcia-Carpizo, V.; Sarmentero, J.; Han, B.; Grana, O.; Ruiz-Llorente, S.; Pisano, D.G.; Serrano, M.; Brooks, H.B.; Campbell, R.M.; Barrero, M.J. NSD2 contributes to oncogenic RAS-driven transcription in lung cancer cells through long-range epigenetic activation. Sci. Rep. 2016, 6, 32952. [CrossRef] [PubMed]

3. Zhu, L.; Yu, C.L.; Zheng, Y. NSD2 inhibition suppresses metastasis in cervical cancer by promoting TGF-beta/TGF-betaRI/SMADs signaling. Biochem. Biophys. Res. Commun. 2019, 519, 489-496. [CrossRef]

4. Aytes, A.; Giacobbe, A.; Mitrofanova, A.; Ruggero, K.; Cyrta, J.; Arriaga, J.; Palomero, L.; Farran-Matas, S.; Rubin, M.A.; Shen, M.M.; et al. NSD2 is a conserved driver of metastatic prostate cancer progression. Nat. Commun. 2018, 9, 5201. [CrossRef] [PubMed]

5. Kuo, A.J.; Cheung, P.; Chen, K.; Zee, B.M.; Kioi, M.; Lauring, J.; Xi, Y.; Park, B.H.; Shi, X.; Garcia, B.A.; et al. NSD2 links dimethylation of histone $\mathrm{H} 3$ at lysine 36 to oncogenic programming. Mol. Cell 2011, 44, 609-620. [CrossRef] 
6. Dai, J.; Jiang, L.; Qiu, L.; Shao, Y.; Shi, P.; Li, J. WHSC1 Promotes Cell Proliferation, Migration, and Invasion in Hepatocellular Carcinoma by Activating mTORC1 Signaling. Onco Targets Ther. 2020, 13, 7033-7044. [CrossRef]

7. Zhang, J.; Lu, J.; Chen, Y.; Li, H.; Lin, L. WHSC1 promotes wnt/beta-catenin signaling in a FoxM1-dependent manner facilitating proliferation, invasion and epithelial-mesenchymal transition in breast cancer. J. Recept. Signal. Transduct. Res. 2020, 40, 410-418. [CrossRef]

8. Want, M.Y.; Tsuji, T.; Singh, P.K.; Thorne, J.L.; Matsuzaki, J.; Karasik, E.; Gillard, B.; Cortes Gomez, E.; Koya, R.C.; Lugade, A.; et al. WHSC1/NSD2 regulates immune infiltration in prostate cancer. J. Immunother. Cancer 2021, 9, e001374. [CrossRef]

9. Foster, B.A.; Gingrich, J.R.; Kwon, E.D.; Madias, C.; Greenberg, N.M. Characterization of prostatic epithelial cell lines derived from transgenic adenocarcinoma of the mouse prostate (TRAMP) model. Cancer Res. 1997, 57, 3325-3330.

10. Ager, C.R.; Reilley, M.J.; Nicholas, C.; Bartkowiak, T.; Jaiswal, A.R.; Curran, M.A. Intratumoral STING Activation with T-cell Checkpoint Modulation Generates Systemic Antitumor Immunity. Cancer Immunol. Res. 2017, 5, 676-684. [CrossRef]

11. Philippou, Y.; Sjoberg, H.T.; Murphy, E.; Alyacoubi, S.; Jones, K.I.; Gordon-Weeks, A.N.; Phyu, S.; Parkes, E.E.; Gillies McKenna, W.; Lamb, A.D.; et al. Impacts of combining anti-PD-L1 immunotherapy and radiotherapy on the tumour immune microenvironment in a murine prostate cancer model. Br. J. Cancer 2020, 123, 1089-1100. [CrossRef] [PubMed]

12. Gubin, M.M.; Esaulova, E.; Ward, J.P.; Malkova, O.N.; Runci, D.; Wong, P.; Noguchi, T.; Arthur, C.D.; Meng, W.; Alspach, E.; et al. High-Dimensional Analysis Delineates Myeloid and Lymphoid Compartment Remodeling during Successful ImmuneCheckpoint Cancer Therapy. Cell 2018, 175, 1014-1030 e19. [CrossRef] [PubMed]

13. Leng, L.; Metz, C.N.; Fang, Y.; Xu, J.; Donnelly, S.; Baugh, J.; Delohery, T.; Chen, Y.; Mitchell, R.A.; Bucala, R. MIF signal transduction initiated by binding to CD74. J. Exp. Med. 2003, 197, 1467-1476. [CrossRef] [PubMed]

14. Wang, H.; Morse, H.C., 3rd. IRF8 regulates myeloid and B lymphoid lineage diversification. Immunol. Res. 2009, 43, 109-117. [CrossRef]

15. Lam, J.H.; Ng, H.H.M.; Lim, C.J.; Sim, X.N.; Malavasi, F.; Li, H.; Loh, J.J.H.; Sabai, K.; Kim, J.K.; Ong, C.C.H.; et al. Expression of CD38 on Macrophages Predicts Improved Prognosis in Hepatocellular Carcinoma. Front. Immunol. 2019, 10, 2093. [CrossRef]

16. Karakasheva, T.A.; Waldron, T.J.; Eruslanov, E.; Kim, S.B.; Lee, J.S.; O’Brien, S.; Hicks, P.D.; Basu, D.; Singhal, S.; Malavasi, F.; et al. CD38-Expressing Myeloid-Derived Suppressor Cells Promote Tumor Growth in a Murine Model of Esophageal Cancer. Cancer Res. 2015, 75, 4074-4085. [CrossRef] [PubMed]

17. McGray, A.J.R.; Huang, R.Y.; Battaglia, S.; Eppolito, C.; Miliotto, A.; Stephenson, K.B.; Lugade, A.A.; Webster, G.; Lichty, B.D.; Seshadri, M.; et al. Oncolytic Maraba virus armed with tumor antigen boosts vaccine priming and reveals diverse therapeutic response patterns when combined with checkpoint blockade in ovarian cancer. J. Immunother. Cancer 2019, 7, 189. [CrossRef]

18. Wang, B.; Li, Q.; Qin, L.; Zhao, S.; Wang, J.; Chen, X. Transition of tumor-associated macrophages from MHC class II(hi) to MHC class II(low) mediates tumor progression in mice. BMC Immunol. 2011, 12, 43. [CrossRef]

19. Rodriguez-Cruz, A.; Vesin, D.; Ramon-Luing, L.; Zuniga, J.; Quesniaux, V.F.J.; Ryffel, B.; Lascurain, R.; Garcia, I.; Chavez-Galan, L. CD3(+) Macrophages Deliver Proinflammatory Cytokines by a CD3- and Transmembrane TNF-Dependent Pathway and Are Increased at the BCG-Infection Site. Front. Immunol. 2019, 10, 2550. [CrossRef]

20. Min, B.K.; Suk, K.; Lee, W.H. Stimulation of CD107 affects LPS-induced cytokine secretion and cellular adhesion through the ERK signaling pathway in the human macrophage-like cell line, THP-1. Cell Immunol. 2013, 281, 122-128. [CrossRef]

21. Kumar, M.P.; Du, J.; Lagoudas, G.; Jiao, Y.; Sawyer, A.; Drummond, D.C.; Lauffenburger, D.A.; Raue, A. Analysis of Single-Cell RNA-Seq Identifies Cell-Cell Communication Associated with Tumor Characteristics. Cell Rep. 2018, 25, 1458-1468 e4. [CrossRef]

22. Dudzinski, S.O.; Cameron, B.D.; Wang, J.; Rathmell, J.C.; Giorgio, T.D.; Kirschner, A.N. Combination immunotherapy and radiotherapy causes an abscopal treatment response in a mouse model of castration resistant prostate cancer. J. Immunother. Cancer 2019, 7, 218. [CrossRef]

23. Gu, S.S.; Wang, X.; Hu, X.; Jiang, P.; Li, Z.; Traugh, N.; Bu, X.; Tang, Q.; Wang, C.; Zeng, Z.; et al. Clonal tracing reveals diverse patterns of response to immune checkpoint blockade. Genome Biol. 2020, 21, 263. [CrossRef] [PubMed]

24. Sade-Feldman, M.; Yizhak, K.; Bjorgaard, S.L.; Ray, J.P.; de Boer, C.G.; Jenkins, R.W.; Lieb, D.J.; Chen, J.H.; Frederick, D.T.; Barzily-Rokni, M.; et al. Defining T Cell States Associated with Response to Checkpoint Immunotherapy in Melanoma. Cell 2018, 175, 998-1013 e20. [CrossRef] [PubMed]

25. Buque, A.; Bloy, N.; Perez-Lanzon, M.; Iribarren, K.; Humeau, J.; Pol, J.G.; Levesque, S.; Mondragon, L.; Yamazaki, T.; Sato, A.; et al. Immunoprophylactic and immunotherapeutic control of hormone receptor-positive breast cancer. Nat. Commun. 2020, 11, 3819. [CrossRef] [PubMed]

26. Olson, B.M.; Gamat, M.; Seliski, J.; Sawicki, T.; Jeffery, J.; Ellis, L.; Drake, C.G.; Weichert, J.; McNeel, D.G. Prostate Cancer Cells Express More Androgen Receptor (AR) Following Androgen Deprivation, Improving Recognition by AR-Specific T Cells. Cancer Immunol. Res. 2017, 5, 1074-1085. [CrossRef] [PubMed]

27. Want, M.Y.; Konstorum, A.; Huang, R.Y.; Jain, V.; Matsueda, S.; Tsuji, T.; Lugade, A.; Odunsi, K.; Koya, R.; Battaglia, S. Neoantigens retention in patient derived xenograft models mediates autologous T cells activation in ovarian cancer. Oncoimmunology 2019, 8, e1586042. [CrossRef] [PubMed]

28. Chen, S.; Zhu, G.; Yang, Y.; Wang, F.; Xiao, Y.T.; Zhang, N.; Bian, X.; Zhu, Y.; Yu, Y.; Liu, F.; et al. Single-cell analysis reveals transcriptomic remodellings in distinct cell types that contribute to human prostate cancer progression. Nat. Cell Biol. 2021, 23, 87-98. [CrossRef] [PubMed]

29. Rohrle, N.; Knott, M.M.L.; Anz, D. CCL22 Signaling in the Tumor Environment. Adv. Exp. Med. Biol 2020, 1231, 79-96. [PubMed] 
30. Rapp, M.; Wintergerst, M.W.M.; Kunz, W.G.; Vetter, V.K.; Knott, M.M.L.; Lisowski, D.; Haubner, S.; Moder, S.; Thaler, R.; Eiber, S.; et al. CCL22 controls immunity by promoting regulatory $\mathrm{T}$ cell communication with dendritic cells in lymph nodes. J. Exp. Med. 2019, 216, 1170-1181. [CrossRef]

31. Hauser, M.A.; Legler, D.F. Common and biased signaling pathways of the chemokine receptor CCR7 elicited by its ligands CCL19 and CCL21 in leukocytes. J. Leukoc. Biol. 2016, 99, 869-882. [CrossRef] [PubMed]

32. Xiong, Y.; Huang, F.; Li, X.; Chen, Z.; Feng, D.; Jiang, H.; Chen, W.; Zhang, X. CCL21/CCR7 interaction promotes cellular migration and invasion via modulation of the MEK/ERK1/2 signaling pathway and correlates with lymphatic metastatic spread and poor prognosis in urinary bladder cancer. Int. J. Oncol. 2017, 51, 75-90. [CrossRef]

33. Kobayashi, D.; Endo, M.; Ochi, H.; Hojo, H.; Miyasaka, M.; Hayasaka, H. Regulation of CCR7-dependent cell migration through CCR7 homodimer formation. Sci. Rep. 2017, 7, 8536. [CrossRef] [PubMed]

34. Kazanietz, M.G.; Durando, M.; Cooke, M. CXCL13 and Its Receptor CXCR5 in Cancer: Inflammation, Immune Response, and Beyond. Front. Endocrinol. (Lausanne) 2019, 10, 471. [CrossRef] [PubMed]

35. Jahchan, N.S.; Mujal, A.M.; Pollack, J.L.; Binnewies, M.; Sriram, V.; Reyno, L.; Krummel, M.F. Tuning the Tumor Myeloid Microenvironment to Fight Cancer. Front. Immunol. 2019, 10, 1611. [CrossRef]

36. Yang, Z.Z.; Kim, H.J.; Villasboas, J.C.; Chen, Y.P.; Price-Troska, T.; Jalali, S.; Wilson, M.; Novak, A.J.; Ansell, S.M. Expression of LAG-3 defines exhaustion of intratumoral PD-1(+) T cells and correlates with poor outcome in follicular lymphoma. Oncotarget 2017, 8, 61425-61439. [CrossRef] [PubMed]

37. Tian, X.; Zhang, A.; Qiu, C.; Wang, W.; Yang, Y.; Qiu, C.; Liu, A.; Zhu, L.; Yuan, S.; Hu, H.; et al. The upregulation of LAG-3 on $\mathrm{T}$ cells defines a subpopulation with functional exhaustion and correlates with disease progression in HIV-infected subjects. $J$. Immunol 2015, 194, 3873-3882. [CrossRef]

38. Blackburn, S.D.; Shin, H.; Haining, W.N.; Zou, T.; Workman, C.J.; Polley, A.; Betts, M.R.; Freeman, G.J.; Vignali, D.A.; Wherry, E.J. Coregulation of CD8+ T cell exhaustion by multiple inhibitory receptors during chronic viral infection. Nat. Immunol. 2009, 10, 29-37. [CrossRef]

39. Derre, L.; Rivals, J.P.; Jandus, C.; Pastor, S.; Rimoldi, D.; Romero, P.; Michielin, O.; Olive, D.; Speiser, D.E. BTLA mediates inhibition of human tumor-specific CD8+ T cells that can be partially reversed by vaccination. J. Clin. Invest. 2010, 120, 157-167. [CrossRef]

40. Laurie, S.J.; Liu, D.; Wagener, M.E.; Stark, P.C.; Terhorst, C.; Ford, M.L. 2B4 Mediates Inhibition of CD8(+) T Cell Responses via Attenuation of Glycolysis and Cell Division. J. Immunol. 2018, 201, 1536-1548. [CrossRef]

41. Vigano, S.; Banga, R.; Bellanger, F.; Pellaton, C.; Farina, A.; Comte, D.; Harari, A.; Perreau, M. CD160-associated CD8 T-cell functional impairment is independent of PD-1 expression. PLoS Pathog. 2014, 10, e1004380. [CrossRef] [PubMed]

42. Chibueze, C.E.; Yoshimitsu, M.; Arima, N. CD160 expression defines a uniquely exhausted subset of T lymphocytes in HTLV-1 infection. Biochem. Biophys. Res. Commun. 2014, 453, 379-384. [CrossRef]

43. Hsu, J.; Hodgins, J.J.; Marathe, M.; Nicolai, C.J.; Bourgeois-Daigneault, M.C.; Trevino, T.N.; Azimi, C.S.; Scheer, A.K.; Randolph, H.E.; Thompson, T.W.; et al. Contribution of NK cells to immunotherapy mediated by PD-1/PD-L1 blockade. J. Clin. Invest. 2018, 128, 4654-4668. [CrossRef]

44. Baggiolini, M. Chemokines in pathology and medicine. J. Intern. Med. 2001, 250, 91-104. [CrossRef]

45. Gao, J.Q.; Okada, N.; Mayumi, T.; Nakagawa, S. Immune cell recruitment and cell-based system for cancer therapy. Pharm. Res. 2008, 25, 752-768. [CrossRef]

46. Karakikes, I.; Morrison, I.E.; O’Toole, P.; Metodieva, G.; Navarrete, C.V.; Gomez, J.; Miranda-Sayago, J.M.; Cherry, R.J.; Metodiev, M.; Fernandez, N. Interaction of HLA-DR and CD74 at the cell surface of antigen-presenting cells by single particle image analysis. FASEB J. 2012, 26, 4886-4896. [CrossRef] [PubMed]

47. Schwartz, V.; Lue, H.; Kraemer, S.; Korbiel, J.; Krohn, R.; Ohl, K.; Bucala, R.; Weber, C.; Bernhagen, J. A functional heteromeric MIF receptor formed by CD74 and CXCR4. FEBS Lett. 2009, 583, 2749-2757. [CrossRef] [PubMed]

48. Bernhagen, J.; Krohn, R.; Lue, H.; Gregory, J.L.; Zernecke, A.; Koenen, R.R.; Dewor, M.; Georgiev, I.; Schober, A.; Leng, L.; et al. MIF is a noncognate ligand of CXC chemokine receptors in inflammatory and atherogenic cell recruitment. Nat. Med. 2007, 13, 587-596. [CrossRef] [PubMed]

49. Wang, X.; Russell-Lodrigue, K.E.; Ratterree, M.S.; Veazey, R.S.; Xu, H. Chemokine receptor CCR5 correlates with functional CD8(+) T cells in SIV-infected macaques and the potential effects of maraviroc on T-cell activation. FASEB J. 2019, 33, 8905-8912. [CrossRef] [PubMed]

50. Contento, R.L.; Molon, B.; Boularan, C.; Pozzan, T.; Manes, S.; Marullo, S.; Viola, A. CXCR4-CCR5: A couple modulating T cell functions. Proc. Natl. Acad. Sci. USA 2008, 105, 10101-10106. [CrossRef]

51. Li, G.; Liang, X.; Lotze, M.T. HMGB1: The Central Cytokine for All Lymphoid Cells. Front. Immunol. 2013, 4, 68. [CrossRef] [PubMed]

52. Bleul, C.C.; Farzan, M.; Choe, H.; Parolin, C.; Clark-Lewis, I.; Sodroski, J.; Springer, T.A. The lymphocyte chemoattractant SDF-1 is a ligand for LESTR/fusin and blocks HIV-1 entry. Nature 1996, 382, 829-833. [CrossRef]

53. Salcedo, R.; Wasserman, K.; Young, H.A.; Grimm, M.C.; Howard, O.M.; Anver, M.R.; Kleinman, H.K.; Murphy, W.J.; Oppenheim, J.J. Vascular endothelial growth factor and basic fibroblast growth factor induce expression of CXCR4 on human endothelial cells: In vivo neovascularization induced by stromal-derived factor-1alpha. Am. J. Pathol. 1999, 154, 1125-1135. [CrossRef]

54. Hughes, C.E.; Nibbs, R.J.B. A guide to chemokines and their receptors. FEBS J. 2018, 285, 2944-2971. [CrossRef] 
55. Giner, G.; Smyth, S.G. Statmod: Probability calculations for the inverse Gaussian distribution. R. J. 2016, 8, 339-351. [CrossRef]

56. Hao, Y.; Hao, S.; Andersen-Nissen, E.; Mauck, W.M., 3rd; Zheng, S.; Butler, A.; Lee, M.J.; Wilk, A.J.; Darby, C.; Zager, M.; et al. Integrated analysis of multimodal single-cell data. Cell 2021, 184, 3573-3587.e29. [CrossRef]

57. van Dijk, D.; Sharma, R.; Nainys, J.; Yim, K.; Kathail, P.; Carr, A.J.; Burdziak, C.; Moon, K.R.; Chaffer, C.L.; Pattabiraman, D.; et al. Recovering Gene Interactions from Single-Cell Data Using Data Diffusion. Cell 2018, 174, 716-729 e27. [CrossRef]

58. Korotkevich, G.; Sukhov, V.; Budin, N.; Shpak, B.; Artyomov, M.N.; Sergushichev, A. Fast gene set enrichment analysis. bioRxiv 2019. [CrossRef]

59. Csardi, G.; Nepusz, T. The igraph software package for complex network research. Inter. J. Complex Syst. 2006, 1695, 1-9.

60. Bhattacharya, A.; Hamilton, A.M.; Furberg, H.; Pietzak, E.; Purdue, M.P.; Troester, M.A.; Hoadley, K.A.; Love, M.I. An approach for normalization and quality control for NanoString RNA expression data. Brief Bioinform. 2021, 22, bbaa163. [CrossRef] [PubMed]

61. Love, M.I.; Huber, W.; Anders, S. Moderated estimation of fold change and dispersion for RNA-seq data with DESeq2. Genome Biol. 2014, 15, 550. [CrossRef] [PubMed]

62. Yu, G.; Wang, L.G.; Yan, G.R.; He, Q.Y. DOSE: An R/Bioconductor package for disease ontology semantic and enrichment analysis. Bioinformatics 2015, 31, 608-609. [CrossRef] [PubMed] 